\title{
KMT2A-ENL Fusion Protein Expression
}

National Cancer Institute

\section{Source}

National Cancer Institute. KMT2A-ENL Fusion Protein Expression. NCI Thesaurus. Code C38391.

Expression of a fusion protein that results from a t(11;19)(q23;p13.3) translocation which fuses the $5^{\prime}$ half of the KMT2A gene to most of the MLLT1 gene and is associated with acute lymphoblastic leukemia and other leukemia types. 